\title{
Efficacy and safety of travoprost/timolol vs dorzolamide/timolol in patients with open-angle glaucoma or ocular hypertension
}

This article was published in the following Dove Press journal:

Clinical Ophthalmology

12 November 2009

Number of times this article has been viewed

\author{
Miguel A Teus' \\ Stefano Miglior ${ }^{2}$ \\ Guna Laganovska ${ }^{3}$ \\ Lāsma Volksone ${ }^{4}$ \\ Bozena Romanowska-Dixon ${ }^{5}$ \\ Roman Gos ${ }^{6}$ \\ Gábor Holló 7 \\ for the C-05-25 Study Group ${ }^{8}$
}

'Hospital Príncipe de Astúrias, Universidad de Alcalá, Madrid, Spain;

${ }^{2}$ Clinica Oculistica, Policlinico di

Monza Università di Milano Bicocca,

Monza (MI), Italy; ${ }^{3}$ Department of

Ophthalmology, Stradina Clinical

University Hospital, Riga, Latvia;

${ }^{4}$ Glaucoma Service, Clinical Hospital

Gailezera, Riga, Latvia; ${ }^{5}$ Szpital

Uniwersytecki w Krakowie, Kraków,

Poland; ${ }^{6}$ Contact-Med, Sp. z o.o.,

Łódź, Poland; 'Semmelweis University,

Department of Ophthalmology,

Budapest, Hungary; ${ }^{8}$ The C-05-25

Study Group: Members are listed

under Acknowledgments
Correspondence: Miguel A Teus

Hospital Príncipe de Astúrias, Carretera

Alcalá-Meco s/n, Alcalá de Henares,

28805 Madrid, Spain

$\mathrm{Tel}+34902$ I8 1828

Fax $+349 \mid 880$ I8 25

Email mtg00003@teleline.es
Purpose: To compare the intraocular pressure- (IOP-) lowering efficacy of fixed combinations travoprost $0.004 \%$ /timolol $0.5 \%$ and dorzolamide $2 \% /$ timolol $0.5 \%$ in patients with ocular hypertension or open-angle glaucoma.

Methods: In this prospective, multicenter, double-masked, randomized clinical trial, 319 qualifying patients received either travoprost/timolol once daily in the morning $(n=157)$ or dorzolamide/timolol twice daily $(\mathrm{n}=162)$. IOP was assessed morning and evening at 2 and 6 weeks. The primary outcome measure was mean diurnal IOP.

Results: Baseline mean IOP values were similar between groups. Mean pooled diurnal IOP was significantly lower in the travoprost/timolol group $(16.5 \mathrm{mmHg} \pm 0.23)$ than in the dorzolamide/timolol group $(17.3 \mathrm{mmHg} \pm 0.23 ; P=0.011)$. Mean IOP was significantly lower in the travoprost/timolol group compared to the dorzolamide/timolol group at the 9 AM time point both at Week $2(P=0.006)$ and Week $6(P=0.002)$. The travoprost/timolol combination produced mean IOP reductions from baseline of $35.3 \%$ to $38.5 \%$, while the dorzolamide/timolol combination produced mean IOP reductions from baseline of $32.5 \%$ to $34.5 \%$.

Conclusions: The fixed combination travoprost $0.004 \% /$ timolol $0.5 \%$ dosed once daily in the morning demonstrated superior mean diurnal IOP-lowering efficacy compared to dorzolamide $2 \% /$ timolol $0.5 \%$ dosed twice daily in patients with ocular hypertension or open-angle glaucoma.

Keywords: dorzolamide, fixed combination, glaucoma, IOP-lowering therapy, timolol, travoprost

\section{Introduction}

Glaucoma is one of the main causes of blindness and irreversible visual deterioration worldwide. To date, the only treatment that can effectively prevent the development ${ }^{1}$ and progression ${ }^{2}$ of glaucoma is reduction of intraocular pressure (IOP). The most commonly used way of achieving IOP reduction is the use of topical IOP-lowering medications. Monotherapy is frequently not sufficient for reaching the preset target IOP; therefore, many patients require more than one medication to achieve adequate IOP reduction.

Several fixed combinations of commonly used IOP-lowering medications have been developed and are available in various markets worldwide. Most fixed combinations contain timolol, as it can be dosed either once or twice daily and can be combined with prostaglandin analogues, adrenergic agonists, and carbonic anhydrase inhibitors. Compared to concomitant dosing with individual constituents, these combinations offer the convenience of fewer drops per day, fewer bottles to handle by the patients,

submit your manuscript $\mid$ www.dovepress.con 
reduced exposure to preservatives, and elimination of the washout effect of multiple drops. ${ }^{3}$

Travoprost 0.004\%/timolol 0.5\% (DuoTrav ${ }^{\circledR}$; Alcon Laboratories, Fort Worth, Texas, USA) and dorzolamide 2\%/timolol 0.5\% (Cosopt ${ }^{\mathrm{TM}}$; Merck and Co., Whitehouse Station, New York, USA) are different fixed combinations, but both contain timolol $0.5 \%$. To date, no comparative clinical studies have been published with these two agents. The purpose of this study was to compare the IOP-lowering efficacy and safety of these two fixed combinations in patients with ocular hypertension or open-angle glaucoma.

\section{Methods}

This was a prospective, multicenter, randomized, doublemasked clinical trial that was approved by the Ethics Committee of each individual study site and was conducted in accordance with the tenets of the Declaration of Helsinki. All participating patients provided written informed consent before they enrolled in the study.

\section{Patients}

Eligible patients were male or female patients 18 years of age or older, of any race, diagnosed with open-angle glaucoma (with or without pseudoexfoliation or pigment dispersion component) or ocular hypertension. The patients had to be under treatment with one or more topical IOP-lowering drugs and, in the opinion of the investigator, would have benefited from treatment with a combination therapy. To be eligible, patients must have had at least one eye that reached an IOP of $24 \mathrm{mmHg}$ at $9 \mathrm{AM}$ and $21 \mathrm{mmHg}$ at $4 \mathrm{PM}$ at both eligibility visits. IOP must not have exceeded $36 \mathrm{mmHg}$ (or $30 \mathrm{mmHg}$ at study sites in Germany, as per a specific local requirement) at any time point. Contact lens wearers were eligible if they removed their lenses before instilling study medication and did not replace the lenses for at least 15 minutes after instillation.

Exclusion criteria were history of chronic, recurrent, or current inflammatory eye diseases or progressive retinal diseases; history of incisional ocular surgery or ocular trauma within 6 months before the study; ocular laser treatment or ocular surgery, ocular infection within 3 months; history of hypoglycemia or uncontrolled diabetes; contraindication to any study medication; advanced glaucoma (cup-disc ratio $>0.8$ or central visual field loss); or any ocular abnormalities precluding accurate applanation tonometry. In addition, patients were excluded if they required systemic glucocorticoid therapy, could not safely discontinue all IOP-lowering therapies for up to 28 days before the first of two eligibility visits conducted 1 week apart, or used any IOP-influencing medication within
30 days before enrollment. Women of childbearing potential (not surgically sterilized at least 3 months prior the study or not postmenopausal for at least 2 years) were not excluded if they were using a reliable form of birth control; a urine pregnancy test was performed after the completion of the second eligibility visit, before randomization, and then repeated at the exit visit in these patients.

\section{Schedule of visits and assessments}

Potential candidates for the study received information related to the study and were provided the opportunity to discuss the study requirements with the investigator. Patients who agreed to participate and gave their consent attended a screening visit, at which time demographics and medical history were collected and reviewed, visual acuity was assessed, IOP was measured with Goldmann tonometry, gonioscopy and automated threshold perimetry were performed, and anterior and posterior segment evaluation was conducted. Patients who qualified were requested to discontinue their current IOP-lowering medications according to the following schedule: 5 days for miotics and carbonic anhydrase inhibitors (both topical and oral); 14 days for $\alpha$ and $\alpha / \beta$-agonists; and 28 days for $\beta$-blockers, prostaglandin analogues, and fixed combination products. Following washout, two separate eligibility visits were performed one week apart. At each of these eligibility visits, the IOP criteria described above had to be met, interim history was recorded, visual acuity assessed, and slit-lamp examination of the anterior segment was performed. At the completion of the eligibility visits, qualified patients were randomized in a $1: 1$ ratio to receive either travoprost $0.004 \% /$ timolol $0.5 \%$ fixed combination once daily at 9 AM and timolol vehicle once daily at 9 PM, or dorzolamide $2 \% /$ timolol $0.5 \%$ fixed combination twice daily at $9 \mathrm{AM}$ and $9 \mathrm{PM}$, in both eyes. Patients started their study medication on the evening of the second eligibility visit, and continued their treatment for six weeks. Patients were provided with "morning 9 AM bottles" and "evening 9 PM bottles" for masking purposes. The study visits were scheduled 2 weeks and 6 weeks after randomization. At the Week 2 and Week 6 visits, patients arrived at $9 \mathrm{AM}$ and refrained from morning administration of the study medication until visual acuity was assessed, IOP measured, slit-lamp examination of the anterior segment performed, and any adverse event recorded. Study medication was then instilled, and patients returned at 4 PM for the afternoon IOP measurement. Dilated fundus examination for all patients and repeated urine pregnancy testing for patients of childbearing potential were conducted at the Week 6 visit prior to study exit. 


\section{Data analysis and statistics}

The primary statistical objective of this study was to examine the IOP-lowering efficacy of travoprost $0.004 \% /$ timolol $0.5 \%$ dosed once daily compared to that of dorzolamide $2 \% /$ timolol $0.5 \%$ dosed twice daily. One eye per patient was included in the analysis, even if both eyes were dosed. If only one eye was dosed, the dosed eye was selected for the analysis; if both eyes were dosed, the worst evaluable eye was designated study eye and selected for the analysis. If both eyes met eligibility criteria, the eye with the higher IOP at 9 AM averaged over both eligibility visits was selected as the study eye. If IOP of both eyes was equal at $9 \mathrm{AM}$, the eye with higher IOP measured at 4 PM was used. If IOP was equal for both eyes at $4 \mathrm{PM}$, the right eye was designated the study eye. The primary efficacy endpoint was mean IOP, which was evaluated at 4 time points: $9 \mathrm{AM}$ and $4 \mathrm{PM}$ at each of the 2 follow-up visits (Week 2 and Week 6). At each time point, at least 2 IOP measurements were taken. If the 2 measurements for the same eye differed by $4 \mathrm{mmHg}$ or less, the average IOP for that eye was used. If the 2 measurements differed more than $4 \mathrm{mmHg}$, a third measurement was taken and used as the IOP for that eye.

Hypothesis tests were performed using a repeated measures analysis of variance and the primary inference was based on the comparisons of mean IOP between the two treatment groups across the four on-therapy visits and time points using the intent-to-treat dataset. A chi square test of independence (or Fisher's exact test if one or more expected cell frequencies were $<5$ ) was used to assess differences between treatment groups for each demographic characteristic. Mean IOP change from baseline was estimated using a repeated measures analysis of variance. Descriptive statistics were calculated for IOP, IOP change from baseline, and IOP percent change from baseline. To evaluate the IOP-lowering efficacy throughout the day, IOP was pooled across both time points at each of the two follow-up visits, and the mean value obtained was defined as combined diurnal IOP. The term diurnal is used here to indicate the awake period during the day, rather than a 24-hour period of time, as would be indicated by a diurnal IOP curve.

With 150 patients per group planned, this study had a $96 \%$ power to detect a $1.5 \mathrm{mmHg}$ difference between groups, based on an assumed common standard deviation of $3.5 \mathrm{mmHg}$ and a Type I error of $\alpha=0.05$.

\section{Results}

A total of 319 adult patients were enrolled in this study and randomized to receive either travoprost/timolol $(n=157)$ or dorzolamide/timolol $(\mathrm{n}=162)$. All 319 participants were included in the safety analysis. Three patients were excluded from the intent-to-treat (ITT; $\mathrm{n}=316$ ) analysis due to lack of data on-therapy, and 6 additional patients were excluded from the per-protocol $(\mathrm{PP} ; \mathrm{n}=310)$ analysis, due to protocol deviations (inadequate time interval from dosing to IOP reading, no qualifying IOP at entry, and intraocular surgery less than 6 months prior to study entry). Results of ITT analyses are presented in this report and were confirmed in PP analyses. Baseline patient demographic information for the safety population is provided in Table 1 . No significant differences were observed between treatment groups in any of the demographic characteristics; the same was true for the ITT and PP population data sets. The age (mean \pm SD) of patients in the safety population was $61.7 \pm 10.8$ years. The IOP-lowering medications taken by patients prior to study enrollment are presented in Table 2, with both treatment groups showing a similar breakdown among the therapy classifications.

Mean diurnal IOP values (pooled across 9 AM and 4 PM time points) are illustrated in Figure 1. Baseline mean diurnal IOP values were similar in the travoprost/ timolol $(26.0 \pm 0.18 \mathrm{mmHg})$ and the dorzolamide/timolol $(26.1 \pm 0.18 \mathrm{mmHg})$ groups $(P=0.818)$. Both treatments reduced diurnal IOP at Weeks 2 and 6 from baseline; however, treatment with travoprost/timolol resulted in $0.8 \mathrm{mmHg}$ lower mean diurnal IOP than that with dorzolamide/timolol at each of the two on-therapy visits $(P<0.05)$. A similar difference was observed for travoprost/timolol compared with dorzolamide/timolol when pooled across the two visits (combined; $16.5 \pm 0.23 \mathrm{mmHg}$ vs $17.3 \pm 0.23 \mathrm{mmHg}$, respectively; $P=0.011$ ).

Mean IOP values at the individual time points at baseline, Week 2, Week 6 and Combined (Week $2+$ Week 6) are presented in Table 3. Baseline mean IOP values were similar in the travoprost/timolol and the dorzolamide/timolol groups both at $9 \mathrm{AM}(26.9 \pm 0.19 \mathrm{mmHg}$ and $27.0 \pm 0.19 \mathrm{mmHg}$, respectively, $P=0.652)$ and $4 \mathrm{PM}(25.1 \pm 0.19 \mathrm{mmHg}$ in both groups, $P=0.987$ ). At 9 AM (approximately 24 hours after dosing with travoprost/timolol), mean IOP was significantly lower in the travoprost/timolol group than in the dorzolamide/timolol group, both at Week 2 $(17.0 \pm 0.26 \mathrm{mmHg}$ vs $18.0 \pm 0.25 \mathrm{mmHg} ; P=0.006)$ and Week 6 (16.6 $\pm 0.26 \mathrm{mmHg}$ vs $17.7 \pm 0.25 \mathrm{mmHg} ; P=0.002)$, as well as when combining the 2 visits $(16.8 \pm 0.24 \mathrm{mmHg}$ vs $17.9 \pm 0.24 \mathrm{mmHg} ; P=0.001)$. Although IOP-lowering values favored the travoprost/timolol group compared to the dorzolamide/timolol group at all 4 PM time points, the differences did not reach statistical significance. 
Table I Baseline demographics - safety population $(n=319)$

\begin{tabular}{|c|c|c|c|c|c|c|c|}
\hline & \multicolumn{2}{|c|}{ Total } & \multicolumn{2}{|c|}{ Travoprost/Timolol } & \multicolumn{2}{|c|}{ Dorzolamide/Timolol } & \multirow[t]{2}{*}{$P$-value ${ }^{a}$} \\
\hline & $\mathbf{N}$ & $\%$ & $\mathbf{N}$ & $\%$ & $\mathbf{N}$ & $\%$ & \\
\hline Total & 319 & 100.0 & 157 & 100.0 & 162 & 100.0 & \\
\hline \multicolumn{8}{|l|}{ Age (years) } \\
\hline$<65$ & 190 & 59.6 & 92 & 58.6 & 98 & 60.5 & 0.730 \\
\hline$\geq 65$ & 129 & 40.4 & 65 & 41.4 & 64 & 39.5 & \\
\hline \multicolumn{8}{|l|}{ Age ( $\geq 65$ years) } \\
\hline$\geq 65$ to $<75$ & 89 & 69.0 & 44 & 67.7 & 45 & 70.3 & 0.748 \\
\hline$\geq 75$ to $<85$ & 40 & 31.0 & 21 & 32.3 & 19 & 29.7 & \\
\hline \multicolumn{8}{|l|}{ Sex } \\
\hline Male & 122 & 38.2 & 58 & 36.9 & 64 & 39.5 & 0.638 \\
\hline Female & 197 & 61.8 & 99 & 63.1 & 98 & 60.5 & \\
\hline \multicolumn{8}{|l|}{ Race } \\
\hline Caucasian & 319 & 100.0 & 157 & 100.0 & 162 & 100.0 & \\
\hline \multicolumn{8}{|l|}{ Iris color } \\
\hline Blue & 84 & 26.3 & 39 & 24.8 & 45 & 27.8 & 0.582 \\
\hline Brown & 153 & 48.0 & 72 & 45.9 & 81 & 50.0 & \\
\hline Green & 32 & 10.0 & 18 & 11.5 & 14 & 8.6 & \\
\hline Grey & 20 & 6.3 & 13 & 8.3 & 7 & 4.3 & \\
\hline Hazel & 30 & 9.4 & 15 & 9.6 & 15 & 9.3 & \\
\hline \multicolumn{8}{|l|}{ Diagnosis } \\
\hline Ocular hypertension & 52 & 16.3 & 24 & 15.3 & 28 & 17.3 & 0.784 \\
\hline Open-angle glaucoma & 243 & 76.2 & 119 & 75.8 & 124 & 76.5 & \\
\hline $\begin{array}{l}\text { Open-angle glaucoma } \\
\text { with pigment dispersion }\end{array}$ & 5 & 1.6 & 3 & 1.9 & 2 & 1.2 & \\
\hline $\begin{array}{l}\text { Open-angle glaucoma } \\
\text { with pseudoexfoliation }\end{array}$ & 19 & 6.0 & II & 7.0 & 8 & 4.9 & \\
\hline
\end{tabular}

Notes: Travoprost/Timolol $=$ travoprost $0.004 \% /$ timolol $0.5 \%$. Dorzolamide/Timolol $=$ dorzolamide $2 \% /$ timolol $0.5 \%$.

aP-value from chi-square or Fisher's exact test.

As shown in Table 4, travoprost/timolol produced a mean IOP reduction from the untreated baseline ranging from $8.8 \pm 0.23 \mathrm{mmHg}$ to $10.4 \pm 0.25 \mathrm{mmHg}$, whereas dorzolamide/timolol produced a mean IOP reduction ranging from $8.2 \pm 0.21 \mathrm{mmHg}$ to $9.3 \pm 0.25 \mathrm{mmHg}$. Figure 2 shows that the mean diurnal IOP reductions in the travoprost/ timolol group were significantly greater than those in the dorzolamide/timolol group at Week 2 and Week $6(P<0.05$ for each).

\section{Safety}

The adverse events, related to the use of the study drugs, observed at an incidence of greater than $1 \%$ in the two treatment arms are described in Table 5. The most common treatment-related ocular adverse event was mild eye irritation, occurring in $5.7 \%$ of patients in the travoprost/timolol group and in $4.3 \%$ of patients in the dorzolamide/timolol group. More patients in the travoprost/timolol group than in the dorzolamide/timolol group experienced hyperemia, generally of mild severity and described as conjunctival (5.7\% vs $0.6 \%$, respectively; $P=0.0096)$ or ocular hyperemia $(5.1 \% \mathrm{vs}$ $0.6 \%$, respectively; $P=0.0182$ ). No serious treatment-related adverse events were reported in either group.

In the travoprost/timolol group, 4 patients (2.5\%) stopped the study medication and were discontinued from the study due to ocular treatment-related events (hyperemia, eye pain, conjunctivitis, and hypersensitivity). In the dorzolamide/ timolol group, 1 patient $(0.6 \%)$ stopped the study medication and was discontinued from the study due to a nonocular event (hallucination, considered not related to treatment).

\section{Discussion}

In this study, we compared the IOP-lowering efficacy of two fixed combinations, travoprost $0.004 \% /$ timolol $0.5 \%$ dosed once daily in the morning and dorzolamide $2 \% /$ timolol $0.5 \%$ dosed twice daily, in patients with openangle glaucoma or ocular hypertension. These results were expected to show that travoprost/timolol would have superior 
Table 2 Intraocular pressure- (IOP-) lowering medication at screening - safety population $(\mathrm{n}=319)$

\begin{tabular}{|c|c|c|c|c|}
\hline \multirow[t]{2}{*}{ IOP-lowering medication } & \multicolumn{2}{|c|}{ Travoprost/Timolol $(\mathbf{N}=$ I 57) } & \multicolumn{2}{|c|}{ Dorzolamide/Timolol $(\mathbf{N}=162)$} \\
\hline & $\mathbf{N}^{\mathbf{a}}$ & $\%$ & $\mathbf{N}^{\mathbf{a}}$ & $\%$ \\
\hline Alfa-agonists (AA) & 4 & 2.5 & 3 & 1.9 \\
\hline Beta-blockers (BB) & 25 & 15.9 & 20 & 12.3 \\
\hline Carbonic anhydrase inhibitors (CAI) & 60 & 38.2 & 60 & 37.0 \\
\hline Combination therapy ${ }^{b}$ & 47 & 29.9 & 50 & 30.9 \\
\hline Pilocarpine & 3 & 1.9 & 3 & 1.9 \\
\hline Prostaglandin analogues (PG) & 34 & 21.7 & 44 & 27.2 \\
\hline
\end{tabular}

Notes: ${ }^{\mathrm{a}}$ The total number of patients in each column is higher than $\mathrm{N}$ because patients could be classified under more than one category of IOP-lowering medication.

${ }^{\mathrm{b}}$ Combination therapy $=$ fixed ophthalmic combinations of BB $+\mathrm{CAI}, \mathrm{BB}+\mathrm{PG}$, or BB $+\mathrm{AA}$. Travoprost/Timolol $=$ travoprost $0.004 \% /$ timolol $0.5 \%$. Dorzolamide/Timolol $=$ dorzolamide $2 \% /$ timolol $0.5 \%$

efficacy to dorzolamide/timolol, based on previous studies of travoprost alone compared to the fixed combination of dorzolamide/timolol, in which travoprost produced superior IOP reductions $\mathrm{s}^{10,11}$ and fewer treatment failures. ${ }^{12}$

Our results show that during the day, the fixed combination travoprost/timolol produced a higher IOP-lowering efficacy than the fixed combination dorzolamide/timolol dosed twice daily, at each visit as well as when pooling data across visits. The observed differences were both statistically significant and clinically meaningful; there was a consistent difference of $0.8 \mathrm{mmHg}(P<0.05)$ between the two groups.

Travoprost/timolol produced lower mean diurnal IOP than dorzolamide/timolol. Diurnal reduction of IOP has been associated with a reduced risk of progression of glaucoma in several studies. The Early Manifest Glaucoma Trial showed that every $1 \mathrm{mmHg}$ of IOP reduction was associated with approximately a $10 \%$ reduction in risk of glaucoma progression. ${ }^{13}$
Mean IOP with travoprost/timolol was at least $1.0 \mathrm{mmHg}$ lower than with dorzolamide/timolol at $9 \mathrm{AM}$; these differences were statistically significant at both the Week 2 and Week 6 visits. These results were not unexpected because at the 9 AM time points (12 hours after dosing dorzolamide/ timolol and 24 hours after dosing travoprost/timolol), dorzolamide was likely not to be as effective since its duration of action is less than 8 hours, ${ }^{14}$ whereas travoprost has been shown to be effective more than 48 hours after dosing. ${ }^{15}$ A tendency for lower IOP in the travoprost/timolol group was uniformly present both at Week 2 and Week 6 and for the pooled data, with the difference between the two treatment arms $\geq 0.5 \mathrm{mmHg}$ at the $4 \mathrm{PM}$ time points. Because these time points measured IOP control only 7 hours after dosing, both travoprost/timolol and dorzolamide/timolol were likely to be effective and therefore no significant difference between treatments was observed.

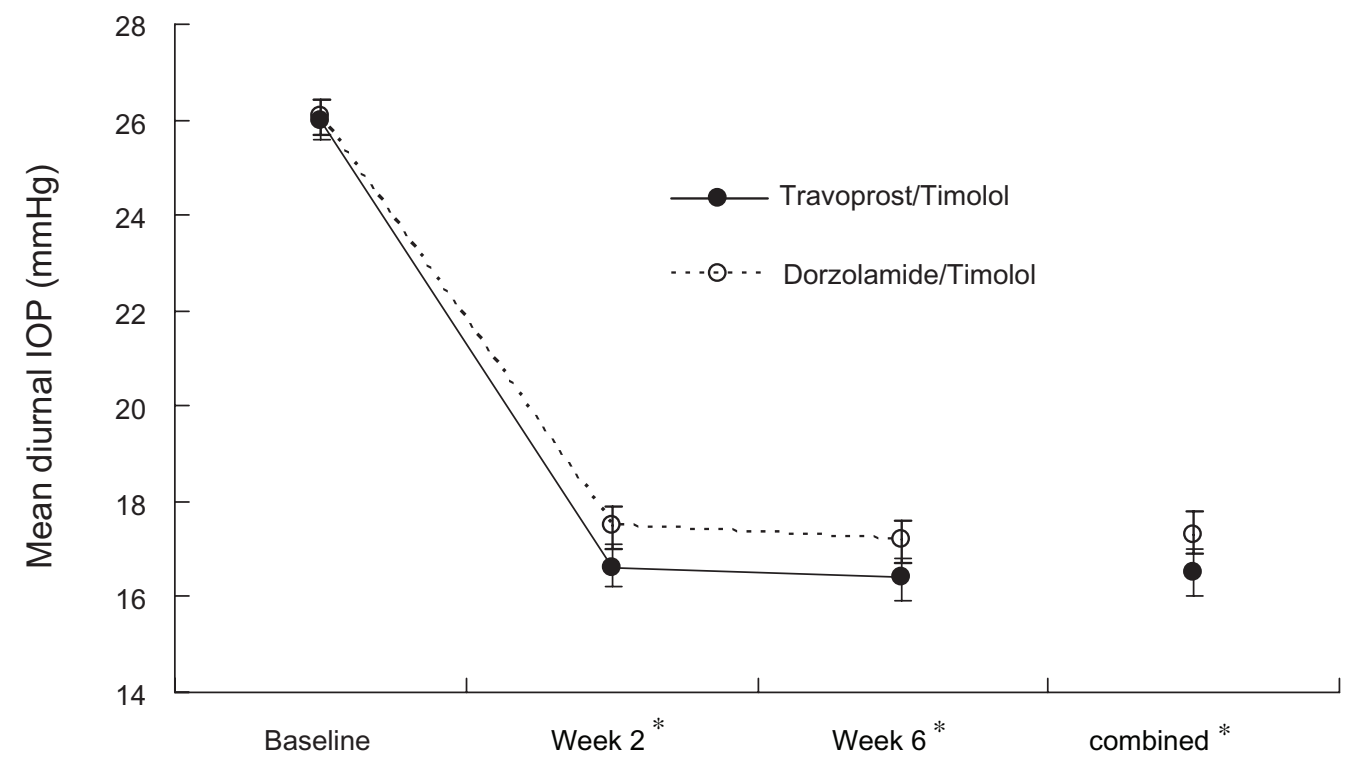

Figure I Mean diurnal intraocular pressure (IOP) ( \pm standard error) across visits.

Notes: $* P<0.05$ for difference in mean diurnal IOP. Travoprost/Timolol $=$ travoprost $0.004 \% /$ timolol $0.5 \%$. Dorzolamide/Timolol $=$ dorzolamide $2 \% /$ timolol $0.5 \%$ 
Table 3 Mean intraocular pressure (IOP) $(\mathrm{mmHg})$ across time points - intent-to-treat population $(\mathrm{n}=316)$

\begin{tabular}{|c|c|c|c|c|c|c|c|c|c|}
\hline & \multicolumn{2}{|c|}{ Baseline } & \multicolumn{2}{|c|}{ Week 2} & \multicolumn{2}{|c|}{ Week 6} & \multicolumn{3}{|c|}{ Combined } \\
\hline & $9 \mathrm{AM}$ & 4 PM & $9 \mathrm{AM}$ & 4 PM & $9 \mathrm{AM}$ & 4 PM & $9 \mathrm{AM}$ & 4 PM & Diurnal \\
\hline \multicolumn{10}{|c|}{ Travoprost/Timolol } \\
\hline Mean & 26.9 & 25.1 & 17.0 & 16.2 & 16.6 & 16.2 & 16.8 & 16.2 & 16.5 \\
\hline SE & 0.19 & 0.19 & 0.26 & 0.26 & 0.26 & 0.26 & 0.24 & 0.24 & 0.23 \\
\hline $\mathrm{N}$ & 154 & 154 & 154 & 154 & 154 & 154 & 154 & 154 & 154 \\
\hline \multicolumn{10}{|c|}{ Dorzolamide/Timolol } \\
\hline Mean & 27.0 & 25.1 & 18.0 & 16.9 & 17.7 & 16.6 & 17.9 & 16.8 & 17.3 \\
\hline SE & 0.19 & 0.19 & 0.25 & 0.25 & 0.25 & 0.25 & 0.24 & 0.24 & 0.23 \\
\hline $\mathrm{N}$ & 162 & 162 & 162 & 161 & 162 & 161 & 162 & 161 & 162 \\
\hline \multicolumn{10}{|l|}{ Difference } \\
\hline Mean & -0.1 & 0.0 & -1.0 & -0.7 & -1.2 & -0.5 & -1.1 & -0.6 & -0.8 \\
\hline SE & 0.27 & 0.27 & 0.36 & 0.36 & 0.36 & 0.36 & 0.34 & 0.34 & 0.32 \\
\hline Upper 95\% CL & 0.4 & 0.5 & -0.3 & 0.0 & -0.4 & 0.2 & -0.4 & 0.1 & -0.2 \\
\hline Lower 95\% CL & -0.7 & -0.5 & -1.7 & -1.4 & -1.9 & -1.2 & -1.7 & -1.2 & -1.5 \\
\hline$P$-value & 0.652 & 0.987 & 0.006 & 0.066 & 0.002 & 0.192 & 0.001 & 0.090 & 0.011 \\
\hline
\end{tabular}

Notes: Travoprost/Timolol $=$ travoprost $0.004 \% /$ timolol $0.5 \%$. Dorzolamide/Timolol $=$ dorzolamide $2 \% /$ timolol $0.5 \%$.

abaseline is the average of the two eligibility visits if both values were not missing, otherwise the nonmissing value of the two visits was used. Combined $=$ results pooled across Week 2 and Week 6. Combined diurnal = mean IOP of all 4 time points ( 9 AM and 4 PM at Week 2 and Week 6 ). Estimates based on least squares means using repeated measures analysis of variance. Baseline estimates obtained from separate model. $P$-values and confidence limits were based on repeated measures analysis of variance.

Abbreviations: $\mathrm{CL}$, confidence limit; SE, standard error.

Travoprost/timolol produced statistically significant and clinically relevant mean IOP reductions from baseline ranging from $8.8 \mathrm{mmHg}(35.3 \%)$ to $10.4 \mathrm{mmHg}(38.5 \%)$. This is consistent with prior studies in which mean IOP reductions ranged from 6.9 to $8.6 \mathrm{mmHg},{ }^{4} 7.4$ to $9.4 \mathrm{mmHg},{ }^{5}$ and 8.8 to $11.5 \mathrm{mmHg} .{ }^{6}$ Dorzolamide/timolol also produced significant and relevant mean IOP reductions from baseline, ranging from $8.2 \mathrm{mmHg}$ (32.5\%) to $9.3 \mathrm{mmHg}$ (34.5\%). This is also consistent with prior data in which mean IOP reductions ranged from 7.7 to $9.0 \mathrm{mmHg}$.

IOP values at Weeks 2 and 6 varied between 16.2 and $17.0 \mathrm{mmHg}$ for travoprost/timolol and between 16.6 and $18.0 \mathrm{mmHg}$ for dorzolamide/timolol. The narrower range for travoprost $0.004 \% /$ timolol $0.5 \%(0.8 \mathrm{mmHg})$ suggests less fluctuation of IOP during the day. Asrani and colleagues suggested that eyes with greater diurnal IOP variation are at increased risk of visual field progression. ${ }^{8}$ Bergea also found that visual field progression was more likely in eyes with higher versus lower diurnal IOP variation. ${ }^{9}$ However, since the data on the relationship between diurnal IOP fluctuation and progression of glaucoma are scarce, the clinical relevance of the narrower range observed in this study remains to be confirmed.

Both therapies evaluated in this study offer numerous benefits that have been previously described for fixed combination products. ${ }^{3}$ Compared to dorzolamide/timolol, the fixed combination travoprost/timolol offers the additional advantage of once-daily dosing. Adherence to therapy improves as the frequency of dosing decreases. ${ }^{16}$ Once-daily dosing is preferred by glaucoma patients and glaucoma specialists alike.

Aside from eye irritation, which was the most prevalent adverse event in both groups, the most frequent ocular event in the travoprost/timolol subjects was conjunctival hyperemia. Eye pruritus was the most frequent ocular event reported in the subjects receiving dorzolamide/timolol. The statistically

Table 4 Descriptive mean intraocular pressure (IOP) and mean IOP change from baseline $(\mathrm{mmHg})$ - intent-to-treat population $(\mathrm{n}=316)$

\begin{tabular}{llllll}
\hline Treatment & \multicolumn{2}{c}{ Week 2 } & & \multicolumn{2}{c}{ Week 6 } \\
\cline { 6 - 7 } \cline { 5 - 6 } & 9 AM & 4 PM & & 9 AM & 4 PM \\
\hline Travoprost/Timolol & & & & \\
$\quad$ Mean IOP & 17.0 & 16.2 & & 16.6 & 16.2 \\
SE IOP & 0.29 & 0.26 & & 0.26 & 0.25 \\
Mean IOP Change & -9.9 & -8.8 & -10.4 & -8.9 \\
SE IOP Change & 0.25 & 0.23 & 0.25 & 0.25 \\
N & 154 & 154 & & 154 & 154 \\
Dorzolamide/Timolol & & & & \\
Mean IOP & 18.0 & 16.9 & & 17.7 & 16.6 \\
SE IOP & 0.25 & 0.23 & & 0.27 & 0.24 \\
Mean IOP Change & -9.0 & -8.2 & -9.3 & -8.5 \\
SE IOP Change & 0.24 & 0.21 & 0.25 & 0.23 \\
N & 162 & 161 & 162 & 161 \\
\hline
\end{tabular}

Notes: Travoprost $/$ Timolol $=$ travoprost $0.004 \% /$ timolol $0.5 \%$. Dorzolamide/ Timolol $=$ dorzolamide $2 \% /$ timolol $0.5 \%$. Descriptive statistics were based on the least square estimates.

Abbreviation: SE, standard error. 


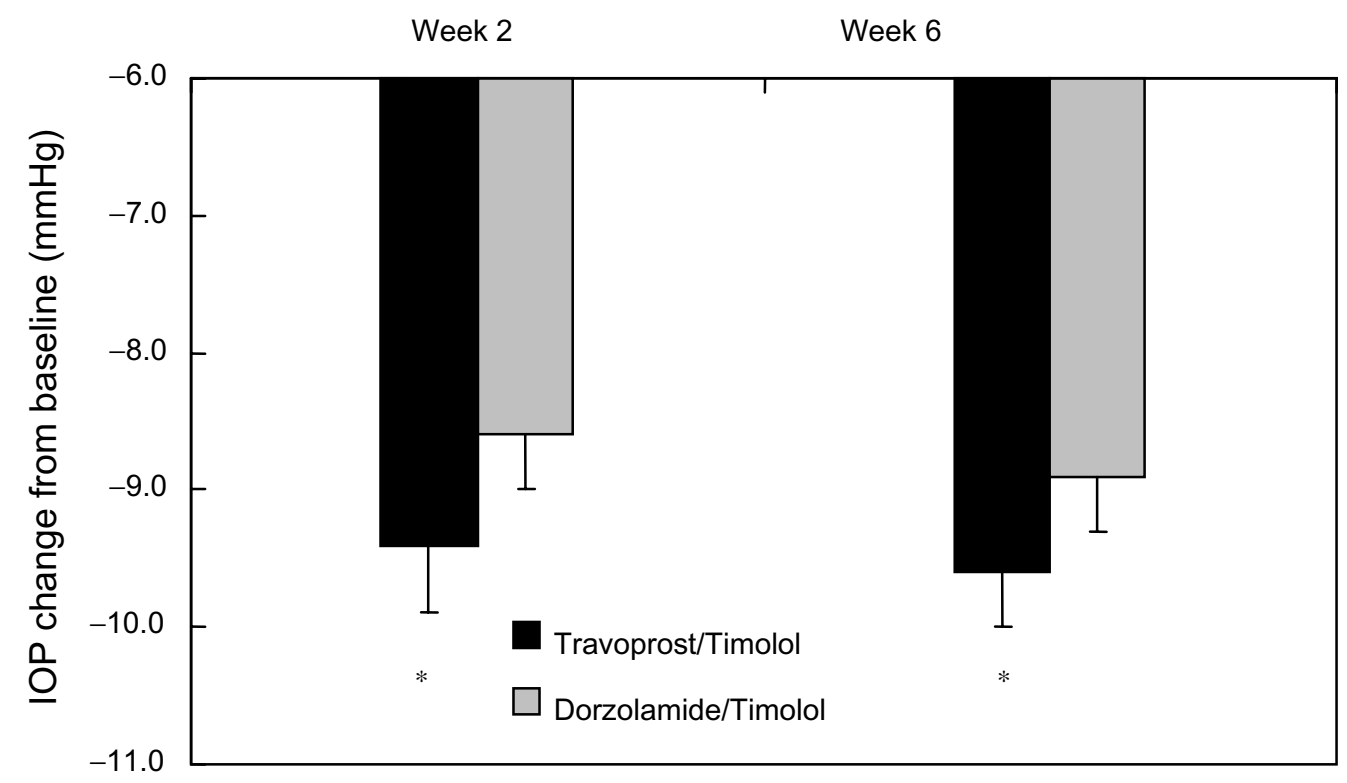

Figure 2 Mean diurnal intraocular pressure (IOP) ( \pm standard error) reduction from baseline.

Notes: $* P<0.05$ for difference in IOP reduction from baseline. Travoprost $/$ Timolol $=$ travoprost $0.004 \% /$ timolol $0.5 \%$. Dorzolamide/Timolol $=$ dorzolamide $2 \% /$ timolol $0.5 \%$

significant differences found between treatment groups in the rates of hyperemia do not represent an untoward safety issue. The incidence of these side effects is consistent with the known safety profile of travoprost $0.004 \%$ /timolol $0.5 \%$. Hyperemia is not unexpected since it is observed frequently with the use of all prostaglandin analogues. Eye pruritus was also an expected ocular event.

In summary, the fixed combination travoprost $0.004 \%$ / timolol $0.5 \%$ dosed once daily in the morning demonstrates superior IOP-lowering efficacy compared to dorzolamide $2 \% /$ timolol $0.5 \%$ dosed twice daily in patients with ocular hypertension or open-angle glaucoma. Both combinations offer the benefits of fixed-combination therapy, but travoprost/timolol offers these benefits with the convenience of once-daily dosing, an attribute valued by both glaucoma patients and their physicians because it encourages patient compliance. ${ }^{16}$

\section{Disclosures}

The authors would like to acknowledge Jennifer Klein, $\mathrm{PhD}$ for medical writing contributions. This assistance was supported by Alcon Research, Ltd. This study was supported by Alcon Research Ltd. as Alcon study C-05-25.

\section{Study registration number}

EudraCT number: 2005-004767-34.

\section{Acknowledgments}

The investigators who participated in this study as members of the C-05-25 Study Group: LATVIA: G Laganovska,

Table 5 Ocular treatment-related adverse events occurring at an incidence of greater than $1 \%-$ safety population $(n=319)$

\begin{tabular}{|c|c|c|c|c|c|}
\hline \multirow{2}{*}{$\begin{array}{l}\text { Ocular adverse drug reaction } \\
\text { coded adverse event }\end{array}$} & \multicolumn{2}{|c|}{ Travoprost/Timolol $\mathbf{N}=157$} & \multicolumn{2}{|c|}{ Dorzolamide/Timolol $N=162$} & \multirow[t]{2}{*}{$P$-value ${ }^{a}$} \\
\hline & $\mathbf{N}$ & $\%$ & $\mathbf{N}$ & $\%$ & \\
\hline Eye irritation & 9 & 5.7 & 7 & 4.3 & 0.5636 \\
\hline Conjunctival hyperemia & 9 & 5.7 & I & 0.6 & 0.0096 \\
\hline Ocular hyperemia & 8 & 5.1 & I & 0.6 & 0.0182 \\
\hline Eye pain & 4 & 2.5 & 2 & 1.2 & 0.4422 \\
\hline Eye pruritus & 3 & 1.9 & 6 & 3.7 & 0.5020 \\
\hline Foreign body sensation & 2 & 1.3 & I & 0.6 & 0.6180 \\
\hline
\end{tabular}

Notes: Coded adverse event $=$ MedDRA Preferred Term (version 10.0). Adverse drug reaction = treatment-related adverse event. Travoprost/Timolol $=$ travoprost $0.004 \% /$ timolol $0.5 \%$. Dorzolamide/Timolol = dorzolamide $2 \% /$ timolol $0.5 \%$.

a $P$-value from chi-square or Fisher's exact test. 
Stradina Clinical University Hospital and L Volksone, Clinical Hospital Gailezera, Riga. FRANCE: JF Rouland, Hôpital Claude Huriez, Lille, Ch-A Ubaud, Marseille, B Delbosc, Hôpital Jean Minjoz, Besançon and JP Bacquaert, Wattrelos. GERMANY: C Erb, Schlosspark-Klinik, Berlin, I Strempel, Augenklinik am Universitätsklinikum, Marburg and G Duncker, Universitätsklinik und Poliklinik für Augenheilkunde, Halle. HUNGARY: G Holló, Semmelweis University Department of Ophthalmology, A Berta, DEOEC, Debrecen, Á Kerényi, Bajcsy-Zsilinszky Hospital, T Milibák, Uzsoki Hospital, Budapest, B Kovács, University Medical and Health Scientific Center, Pécs, K Korompai, BorsodAbaúj-Zemplén County Hospital, Miskolc, L Kolozsvári, University of Szeged, B Kovács, Kaposi Mór Teaching Hospital, Kaposvár, J Győri, Cholnoki Ferenc Hospital, Veszprém, I Elek, Bugát Pál Hospital, Gyönygös, Z Öri, Vaszary Kolos Hospital, Esztergom and A Bereczki, Petz Aladar County Teaching Hospital, Gyor. ITALY: R Meduri, Azienda Ospedaliera Policlinico S Orsola Malpigli, Bologna, M Fossarello, Ospedale San Giovanni Di Dio, Cagliari, S Miglior, Università di Milano Bicocca, Monza and A Sebastiani, Arcispedale S Anna, Ferrara. POLAND: B Romanowska-Dixon, SPZOZ Szpital Uniwersytecki w Krakowie, Kraków and R Gos, "Contact-Med" Sp z o.o.Łódź. SPAIN: M A Teus, Hospital Principe de Astúrias, Madrid, PC Fernández-Vila, Hospital Provincial, Pontevedra and A Arias-Puente Fundación Hospital Alcorcón. TURKEY: K Andac, Ege University Medical Faculty Bornova-Izmir and K Güngör, University Medical Faculty Gaziantep.

\section{References}

1. Kass MA, Heuer DK, Higginbotham EJ, et al. The Ocular Hypertension Treatment Study: a randomized trial determines that topical ocular hypotensive medication delays or prevents the onset of primary open-angle glaucoma. Arch Ophthalmol. 2002;120(6):701-713; discussion 829-830.

2. Heijl A, Leske MC, Bengtsson B, Hyman L, Bengtsson B, Hussein M. Reduction of intraocular pressure and glaucoma progression: results from the Early Manifest Glaucoma Trial. Arch Ophthalmol. 2002;120(10): 1268-1279.
3. Fechtner RD, Realini T. Fixed combinations of topical glaucoma medications. Curr Opin Ophthalmol. 2004;15(2):132-135.

4. Schuman JS, Katz GJ, Lewis RA, et al. Efficacy and safety of a fixed combination of travoprost $0.004 \% /$ timolol $0.5 \%$ ophthalmic solution once daily for open-angle glaucoma or ocular hypertension. $\mathrm{Am} \mathrm{J}$ Ophthalmol. 2005;140(2):242-250.

5. Hughes BA, Bacharach J, Craven ER, et al. A three-month, multicenter, double-masked study of the safety and efficacy of travoprost $0.004 \%$ / timolol $0.5 \%$ ophthalmic solution compared to travoprost $0.004 \%$ ophthalmic solution and timolol $0.5 \%$ dosed concomitantly in subjects with open angle glaucoma or ocular hypertension. J Glaucoma. 2005;14(5):392-399.

6. Barnebey HS, Orengo-Nania S, Flowers BE, et al. The safety and efficacy of travoprost $0.004 \% /$ timolol $0.5 \%$ fixed combination ophthalmic solution. Am J Ophthalmol. 2005;140(1):1-7.

7. Boyle JE, Ghosh K, Gieser DK, Adamsons IA. A randomized trial comparing the dorzolamide-timolol combination given twice daily to monotherapy with timolol and dorzolamide. Dorzolamide-Timolol Study Group. Ophthalmology. 1998;105(10):1945-1951.

8. Asrani S, Zeimer R, Wilensky J, Gieser D, Vitale S, Lindenmuth K. Large diurnal fluctuations in intraocular pressure are an independent risk factor in patients with glaucoma. J Glaucoma. 2000;9(2):134-142.

9. Bergea B, Bodin L, Svedbergh B. Impact of intraocular pressure regulation on visual fields in open-angle glaucoma. Ophthalmology. 1999;106(5):997-1004; discussion 1004-1005.

10. Suzuki ER Jr, Franklin LM, da Silva LJ, Figueiredo CR, Netto JA, Batista WD. Comparison of the efficacy and safety of travoprost with a fixed-combination of dorzolamide and timolol in patients with open-angle glaucoma or ocular hypertension. Curr Med Res Opin. 2006;22(9):1799-1805.

11. Chiseliță D, Antohi I, Medvichi R, Danielescu C. Comparative analysis of the efficacy and safety of latanoprost, travoprost and the fixed combination timolol-dorzolamide; a prospective, randomized, masked, cross-over design study. Oftalmologia. 2005;49(3):39-45.

12. Lafuma A, Berdeaux G. Costs and effectiveness of travoprost versus a dorzolamide + timolol fixed combination in first-line treatment of glaucoma: analysis conducted on the United Kingdom General Practitioner Research Database. Curr Med Res Opin. 2007;23(12):3009-3016.

13. Leske MC, Heijl A, Hyman L, Bengtsson B, Dong L, Yang Z. Predictors of long-term progression in the early manifest glaucoma trial. Ophthalmology. 2007;114(11):1965-1972.

14. Lippa EA, Carlson LE, Ehinger B, et al. Dose response and duration of action of dorzolamide, a topical carbonic anhydrase inhibitor. Arch Ophthalmol. 1992;110(4):495-499.

15. Gross RL, Peace JH, Smith SE, et al. Duration of IOP reduction with travoprost BAK-free solution. J Glaucoma. 2008;17(3):217-222.

16. Patel SC, Spaeth GL. Compliance in patients prescribed eyedrops for glaucoma. Ophthalmic Surg. 1995;26(3):233-236.
Clinical Ophthalmology

\section{Publish your work in this journal}

Clinical Ophthalmology is an international, peer-reviewed journal covering all subspecialties within ophthalmology. Key topics include: Optometry; Visual science; Pharmacology and drug therapy in eye diseases; Basic Sciences; Primary and Secondary eye care; Patient Safety and Quality of Care Improvements. This journal is indexed on Submit your manuscript here: http://www.dovepress.com/clinical-ophthalmology-journal

\section{Dovepress}

PubMed Central and CAS, and is the official journal of The Society of Clinical Ophthalmology (SCO). The manuscript management system is completely online and includes a very quick and fair peer-review system, which is all easy to use. Visit http://www.dovepress.com/ testimonials.php to read real quotes from published authors. 